\title{
Altimetry Combined with Hydrography for Ocean Transport Estimation
}

\author{
Claire Gourcuff, Pascale Lherminier, And Herlé Mercier \\ Laboratoire de Physique des Océans, CNRS-UBO-IFREMER-IRD, IFREMER, Brest, France \\ PiERRE YVES LE TRAON \\ Laboratoire d'Océanographie Spatiale, IFREMER, Brest, France
}

(Manuscript received 13 August 2010, in final form 14 April 2011)

\begin{abstract}
A method to estimate mass and heat transports across hydrographic sections using hydrography together with altimetry data in a geostrophic inverse box model is presented. Absolute surface velocities computed from Archiving, Validation, and Interpretation of Satellite Oceanographic data (AVISO) altimetry products made up of a combination of sea surface height measurements and geoid estimate are first compared to ship acoustic Doppler current profiler (S-ADCP) measurements of the Observatoire de la Variabilité Interannuelle et Décennale (OVIDE) project along hydrographic sections repeated every $2 \mathrm{yr}$ in summer from Portugal to Greenland. The RMS difference between S-ADCP and altimetry velocities averaged on distances of about $100 \mathrm{~km}$ accounts for $3.3 \mathrm{~cm} \mathrm{~s}^{-1}$. Considering that the uncertainty of S-ADCP velocities is found at $1.5 \mathrm{~cm} \mathrm{~s}^{-1}$, altimetry errors are estimated at $3 \mathrm{~cm} \mathrm{~s}^{-1}$. Transports across OVIDE sections previously obtained using S-ADCP data to constrain the geostrophic inverse box model are used as a reference. The new method is found useful to estimate absolute transports across the sections, as well as part of their variability. Despite associated uncertainties that are about 50\% larger than when S-ADCP is used, the results for the North Atlantic Current and heat transports, with uncertainties of $10 \%-15 \%$, reproduce the already observed variability. The largest uncertainties are found in the estimates of the East Greenland Irminger Current (EGIC) transport $(30 \%)$, induced by larger uncertainties associated with altimetry data at the western boundary.
\end{abstract}

\section{Introduction}

With more than 15 yr of continuous measurements, sea surface height ( $\mathrm{SSH}$ ) data from satellite altimetry have become a key source of ocean observations, providing complementary information to in situ measurements. The simultaneous satellite missions available since 1992 (up to four) afford an accurate description of the variability of ocean surface currents on weekly to decadal time scales from the mesoscale to basin scale (Ducet et al. 2000). Thanks to the progress made in geoid models during the last decade, a $1 / 2^{\circ}$ resolution mean dynamical topography (MDT) has been estimated (Rio and Hernandez 2004; Rio et al. 2005), based on the Eigen-Gravity Recovery and Climate Experiment (GRACE) 03S geoid

Corresponding author address: Claire Gourcuff, Laboratoire de Physique des Océans, Centre IFREMER de Brest, BP 70, 29280 Plouzané, France.

E-mail: claire.gourcuff@ifremer.fr model, the Collecte Localisation Satellites (CLS) 01 mean $\mathrm{SSH}$, and a considerable number of in situ and altimetry ocean data. Combined with altimetry $\mathrm{SSH}$ anomaly [or sea level anomaly (SLA)], the MDT leads to the absolute geostrophic surface currents since 1992 on a global view.

Through the hypothesis of a large-scale ocean circulation in geostrophic equilibrium and hydrostatic balance, altimetry measurements could be of major interest in the estimation of the reference-level velocity, which is needed to get absolute velocity of the water column from hydrography (Joyce et al. 1986; Fu and Chelton 2001). In the description of the large-scale ocean circulation from hydrography, the reference-level velocity, when different from zero, can be adjusted from climatology values (Álvarez et al. 2004) or from different sources of measurements, like acoustic Doppler current profilers (ADCP) or floats (Bersch 1995; Krauss 1995; Bacon 1997; Joyce et al. 2001; Lherminier et al. 2007), or, more recently, satellite altimetry data (Sarafanov et al. 2010). Mass or tracer conservation is generally added to 
improve the estimation of the circulation. Lumpkin et al. (2008) quantitatively showed the impact of a referencelevel velocity adjustment compared to the level of no motion hypothesis. They showed an increase of $50 \%$ in the transport of the intermediate layer in an adjusted velocity case, thus highlighting the need for a precise reference velocity estimation.

Inverse methods represent a remarkable tool for solving the problem of reference-level velocity estimation in the geostrophic balance (Wunsch 1978, 1996). In their study of circulation across a meridional World Ocean Circulation Experiment (WOCE) hydrographic section at $66^{\circ} \mathrm{W}$, Joyce et al. (2001) pointed out the utility of lowered ADCP data in adding information to their circulation based on geostrophy and conservation constraints in inverse computations. In the recent work of Lherminier et al. $(2007,2010)$ and Gourcuff $(2008)$ it is shown that a geostrophic box inverse model constrained with direct current measurements from ship ADCP (S-ADCP) enables an accurate determination of the total top-to-bottom absolute velocity field across a hydrographic section. The method has been performed in four sections-the A25 section of the World Ocean Circulation Experiment (Fourex 1997) and OVIDE 2002, 2004, and 2006-implemented along a similar path in the subpolar North Atlantic. The accuracy of the resulting transport values makes it possible to study the variability of the circulation between two repeats. Lherminier et al. (2007) also compare revisited transports across Fourex 1997, constrained with direct current measurements from S-ADCP with previous transport results constrained with climatology (Álvarez et al. 2004). The comparison underlines the importance of constraining the inverse model with direct current measurements coincident in time with the hydrographic data if one wants to study the variability of the circulation.

In their study regarding the combination of Ocean Topography Experiment (TOPEX)/Poseidon data with a hydrographic inversion, Ganachaud et al. (1997) concluded that the geoid model available in the 1990s, computed using the Joint Gravity Model (JGM)-3 gravity field solution (Tapley et al. 1996), was not precise enough to improve our knowledge of ocean circulation from altimetry data. Nevertheless, the authors also showed the impact of a hypothetical improved geoid on the reduction of uncertainty on ocean circulation.

Since 1997, geoid accuracy has improved significantly (Reigber et al. 2003; Bruinsma et al. 2010). The aim of the present paper is thus to evaluate the ability of altimetry data combined with the geoid presently available to improve the 3D ocean circulation, and more precisely the reference-level velocity estimates.

With the objective of using altimetry data to constrain our inverse geostrophic box model (Lherminier et al.

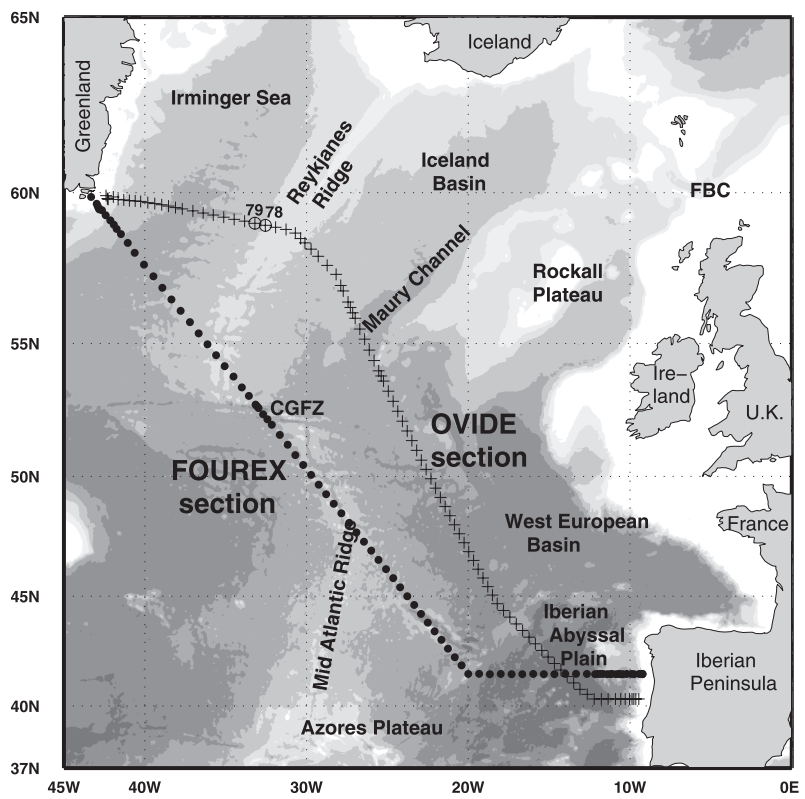

FIG. 1. OVIDE and Fourex sections and main bathymetry structures. CGFZ: Charlie Gibbs Fracture Zone Fracture, BFZ: Bight Fracture Zone, and FBC: Faroe Bank Channel.

2007), we first compare collocated (in time and space) S-ADCP velocities with velocities calculated from altimetry measurements (data presented in section 2). The comparison (section 3 ) helps us to estimate uncertainty on absolute altimetry velocities, a critical element for the inverse process. The detailed method allowing absolute top-to-bottom transport determination across a hydrographic section is described in section 4 . Results are then discussed in section 5 .

\section{Data}

The study was performed in the framework of the Observatoire de la Variabilité Interannuelle à Decennale (OVIDE) project, which occupied a transoceanic hydrographic section from Greenland to Portugal every other year starting in 2002. The chosen section crossed the main currents that form the North Atlantic meridional overturning circulation and was close to the Fourex section performed in August 1997 (Fig. 1). Each section consists of about 100 CTD stations. In the following a pair of stations refers to two CTD stations that are consecutive along the hydrographic section. Data from four cruises-Fourex 1997 and OVIDE 2002, 2004, and 2006 (Table 1)-were used in order to compare the altimetry with ADCP data, and to estimate transports using altimetry combined with hydrography data. In addition to the classical CTD measurements, velocity data were collected during each of the four cruises, from two 
TABLE 1. Cruise information.

\begin{tabular}{lllll}
\hline & \multicolumn{1}{c}{ Fourex 1997 } & \multicolumn{1}{c}{ OVIDE 2002 } & \multicolumn{1}{c}{ OVIDE 2004 } & OVIDE 2006 \\
\hline Chief Scientist & S. Bacon & H. Mercier & T. Huck & P. Lherminier \\
Vessel & RSS Discovery & Research Vessel (R/V) Thalassa & R/V Thalassa & M.S. Merian \\
Dates & 9-31 Aug & 18 Jun-10 Jul & 13 Jun-3 Jul & 25 May-22 Jun \\
S-ADCP & RDI 150 kHz & RDI 75 kHz & RDI 75 kHz and RDI 150 kHz & RDI OS 75 kHz \\
Reference & Lherminier et al. (2007) & Lherminier et al. (2007) & Lherminier et al. (2010) & Gourcuff (2008) \\
\hline
\end{tabular}

lowered ADCP fixed on the rosette and from an S$\mathrm{ADCP}$, with the latter measuring currents in the several first hundred meters along the ship track.

Lherminier et al. (2007) provide an analysis of data, transports, and water mass properties of the first OVIDE section occupied in June 2002, compared with Fourex 1997. OVIDE 2004 is presented in Lherminier et al. (2010) and OVIDE 2006 is in Gourcuff (2008).

\section{a. S-ADCP data}

S-ADCPs have the advantage of sampling currents underway, as long as the ship velocity is properly removed using the navigation data. The four beams of the instrument usually ping every 2 or $3 \mathrm{~s}$, and velocity profiles are calculated as averages of between 20 and 50 values, after removing the ship velocity. In this study the vertical resolution of the S-ADCP profiles is $16 \mathrm{~m}$. For a typical vessel speed of around $10 \mathrm{kt}$, the instrument therefore returns a velocity profile with a spatial resolution ranging from 250 to $625 \mathrm{~m}$ along the ship track, that is, a very high resolution. Table 1 details the S-ADCP data of the four cruises with cross references to a dedicated study for each cruise.

Geostrophic velocities can be calculated relative to a reference level by using hydrographic data, but the thermal wind equation only gives access to the component perpendicular to the station pair line. This is why we focus in this paper on the component of the SADCP velocities that is perpendicular to the section.
Figure 2 shows, as an example, S-ADCP velocities averaged on 1-km cells between station 78 and 79 of OVIDE 2006 (the western flank of the Reykjanes Ridge, see Fig. 1) in a distance-depth plane. It displays the performance of the M.S. Merian S-ADCP used during OVIDE 2006, with a penetration depth of almost $800 \mathrm{~m}$ in this area of the Irminger Sea, and the high variability of velocity along the $35-\mathrm{km}$ distance between stations 78 and 79 .

The quality and penetration depth of the signal measured by an S-ADCP relies on different parameters: the instrument itself, the chosen configuration and the weather conditions. Thanks to the accuracy of the actual navigation data, it is now possible to measure currents en route from S-ADCP measurements averaged over several hours with a precision of $1 \mathrm{~cm} \mathrm{~s}^{-1}$ (Saunders and King 1995; King et al. 2001; Fischer et al. 2003). S-ADCP measurements carried out during stations were compared with independent lowered ADCP measurements, showing a very good agreement (with a root-meansquare difference of $\sim 2 \mathrm{~cm} \mathrm{~s}^{-1}$ for OVIDE 2006 data averaged in the 100-400-m layer), thus demonstrating the good quality of the global S-ADCP dataset.

When comparing to geostrophic velocities, a representativeness error must be taken into account in the S-ADCP measurements, corresponding to ageostrophic velocities. Saunders and King (1995) concluded from a comparison between geostrophic velocities computed from CTD measurements with a level of no motion at

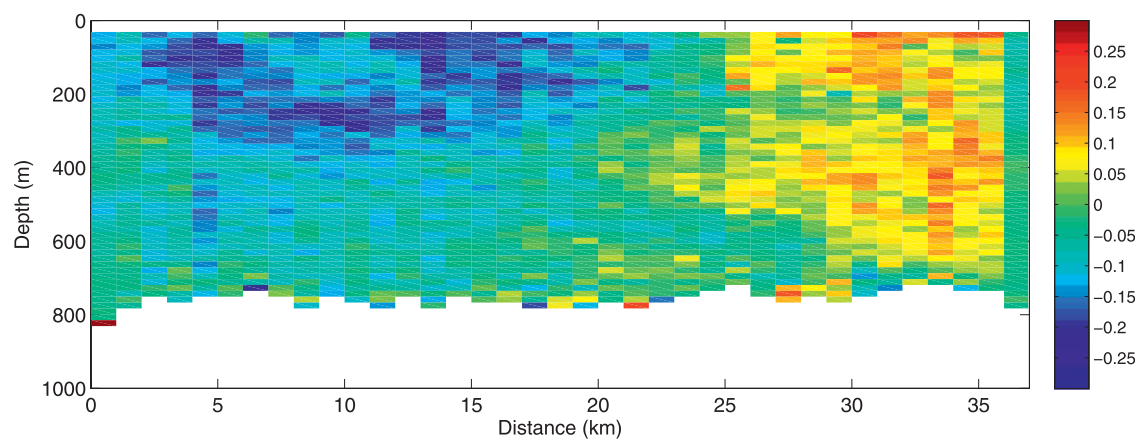

FIG. 2. S-ADCP velocities $\left(\mathrm{m} \mathrm{s}^{-1}\right)$ perpendicular to the OVIDE 2006 section in the Irminger Sea between stations 78 and 79 (Fig. 1), presented on a depth-distance plan. The color bar shows the intensity of velocities, positive to the north and negative to the south. 
$4000 \mathrm{~m}$ and S-ADCP measurements that this error could amount to up to $5 \mathrm{~cm} \mathrm{~s}^{-1}$ for velocities between stations $75 \mathrm{~km}$ apart. However, this crude estimate of $5 \mathrm{~cm} \mathrm{~s}^{-1}$ also contains the error resulting from the velocity at the reference level, which is not necessarily equal to zero, as well as the tide component. Here the barotropic tide velocities component has been removed from S-ADCP velocities from the global $1 / 4^{\circ}$ tide model of Egbert et al. (1994). The $5 \mathrm{~cm} \mathrm{~s}^{-1}$ estimate must then be considered as too high.

A way to estimate the contribution of all of the ageostrophic currents in the S-ADCP datasets is to compare vertical velocity shear obtained from CTD and from $\mathrm{S}$-ADCP in the subsurface layer, which is chosen for each cruise to avoid the mixed layer while ensuring enough S-ADCP measurements. Ekman velocity can be an important part of the subsurface velocity. According to Rio and Hernandez (2003) who used two different models of the Ekman velocity, the Ekman component can reasonably be neglected under the depth of $50 \mathrm{~m}$ at subpolar latitudes in summer. The difference between S-ADCP and geostrophic velocity shears were thus computed for each pair of stations in the 50-200-m layer for the $75-\mathrm{kHz}$ S-ADCPs and the 50-150-m layer for the 150-kHz S-ADCPs (Table 1). Once integrated over depth, we found a mean difference of $2.4 \mathrm{~cm} \mathrm{~s}^{-1}$ for OVIDE cruises and $4 \mathrm{~cm} \mathrm{~s}^{-1}$ for Fourex cruise, showing that when associated with an error of $2-4 \mathrm{~cm} \mathrm{~s}^{-1}$, S-ADCP velocities can be considered as mainly geostrophic in subsurface layers [as was also noted by Bersch (1995) in the same region].

To get the more quantitative estimates needed by the inverse computation, we first average S-ADCP velocities en route over $1-\mathrm{km}$ segments and calculate their standard deviation over distances that are equivalent to the Rossby deformation radius (Chelton et al. 1998), which varies from 7 to $25 \mathrm{~km}$ along the OVIDE section (not shown). Then, the interstation error is computed as the averaged of the standard deviations divided by the square root of the number of Rossby deformation radius included in the interstation distance. Finally, we add an estimate of the instrumental noise. For each of the four cruises the computation leads to total uncorrelated errors of the order of 2-4 $\mathrm{cm} \mathrm{s}^{-1}$ for velocities averaged under the mixed layer along the path between two stations (Lherminier et al. 2007), a result consistent with the above shear comparison.

\section{b. Altimetry data}

Surface geostrophic velocities (called altimetry velocities below) were derived from gridded altimetry data of absolute dynamic topography (ADT) provided by Archiving, Validation, and Interpretation of Satellite
Oceanographic data (AVISO), where ADT is the sum of the SLA and MDT. The ADT products used in this study were estimated using the Rio05 mean dynamic topography (Rio et al. 2005). Tests were made with the new Centre National d'Études Spatiales (CNES)-CLS09 MDT but it did not significantly change the results. The multi-mission $1 / 3^{\circ}$ gridded SLA, available every 7 days since October 1992 , and the $12^{\circ}$ Rio05 MDT were linearly interpolated at the locations of the stations of all of the hydrographic sections-and at the given dates for the SLA-before calculating the ADT. Then, altimetry velocities orthogonal to the sections were calculated for each pair of stations following Eq. (1), derived from the geostrophic balance

$$
v_{p}=\frac{g}{f} \frac{h_{1}-h_{2}}{d_{1-2}},
$$

where $g$ represents the gravity acceleration; $f=2 \Omega \sin \theta$ is the Coriolis parameter, with $\theta$ the latitude and $\Omega$ the angular velocity of the earth's rotation; $h$ stands for the absolute dynamical topography; and $d$ stands for distance. Indexes 1 and 2 denote station numbers of the considered pair $p$.

Two datasets of mapped ADT are distributed by AVISO: a set called ref, which is calculated from no more than two satellites and is homogeneous in time from 1992 to now; and a set called upd, which is calculated with calibrated data from all the satellites available at any given time. The upd series, which represents the most accurate data (CLS 2006), was preferred in this study, but ref data were nevertheless useful for the comparison with ADCP data (see below).

AVISO provides map of uncertainties on gridded sea level anomalies, expressed in percentage of the variance. These uncertainties are formal errors resulting from the multi-mission gridded SLA generation. They take into account sampling pattern and noise measurement characteristics on sea level heights for the scale of the mapping.

The question of mapping altimetry SLA was investigated by Le Traon and Dibarboure (1999, 2002), who showed that mapping errors can be strongly reduced using data from several missions. However, their results also showed that determining errors on velocities is more demanding in terms of sampling, with errors in percentage of the signal variance 2-4 times larger than the uncertainties on the SLA. The estimation of the velocity anomaly mapping error is also more sensitive to the a priori choice of the covariance function (Le Traon and Dibarboure 1999) and its accuracy is strongly limited by high-frequency signals (Le Traon and Dibarboure 2002). 

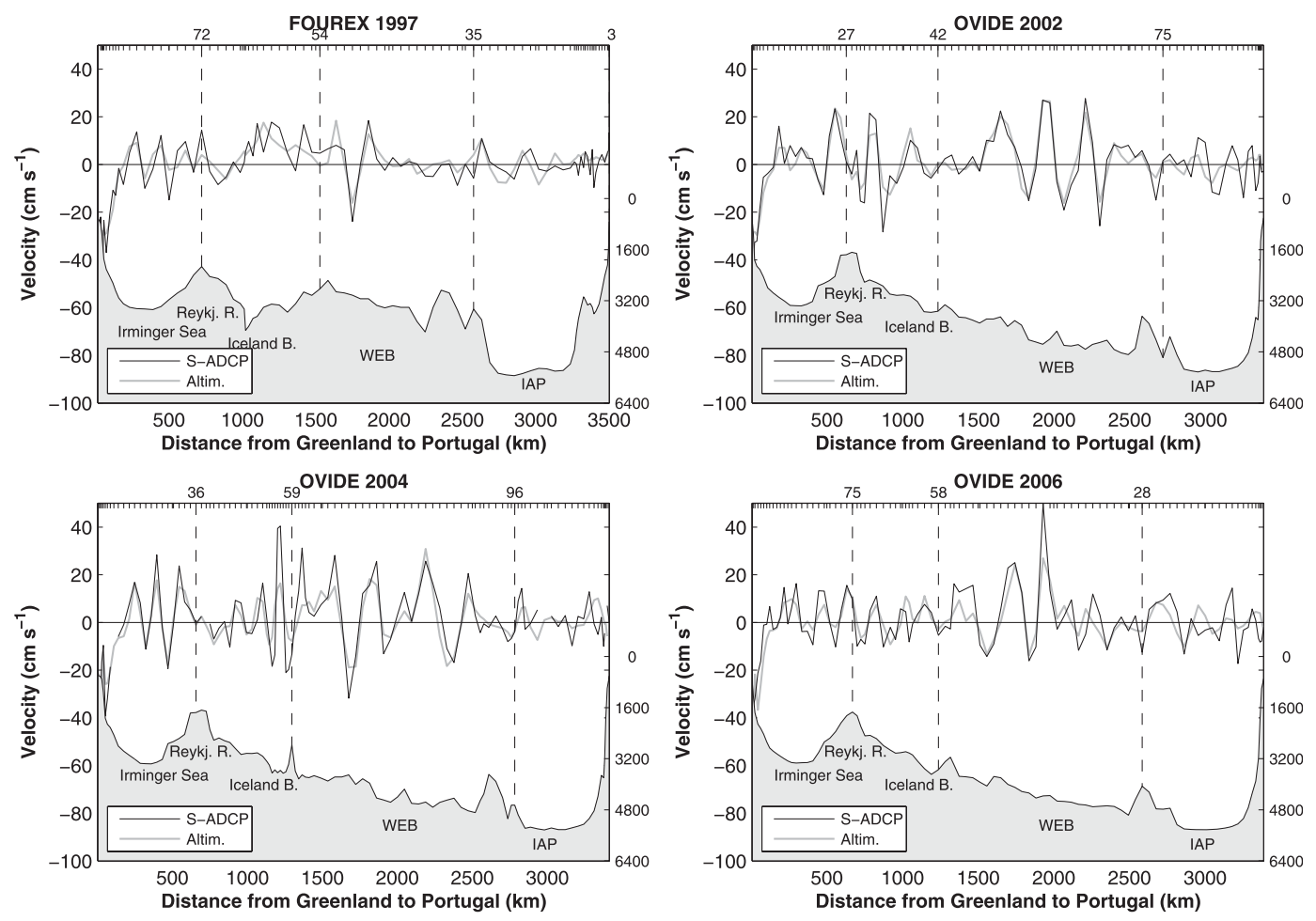

FIG. 3. Comparison (left axes) between altimetry velocities (gray) and S-ADCP velocities (black, $\mathrm{cm} \mathrm{s}^{-1}$ ) for each pair of stations as a function of distance from Greenland (km) for Fourex 1997 and OVIDE 2002, 2004, and 2006. The numbers of the stations (top axis) and bathymetry (right axis) are indicated.

Uncertainties on MDT also contribute significantly to uncertainties on absolute geostrophic velocities derived from altimetry. The only error available for the Rio05 MDT also comes from the mapping procedure. It is known to be underestimated (M.-H. Rio 2006, personal communication) and to only provide information on the relative spatial accuracy of the data.

We will see in the following how an estimate of more realistic uncertainties on absolute altimetry velocities computed from gridded products can be done by comparing them with synoptic ADCP data.

\section{Comparison between altimetry and S-ADCP velocities}

\section{a. Velocities averaged between stations}

S-ADCP velocities were first averaged between the two stations of the pairs for all of the sections to be compared to the collocated altimetry velocity. Altimetry velocity represents the geostrophic part of the velocity field at the surface whereas the S-ADCP measures the total velocity field. We showed previously that by taking into account the associated errors the S-ADCP measurements can be considered geostrophic under $50 \mathrm{~m}$. To compare altimetry and S-ADCP data, S-ADCP data were therefore vertically averaged between 50 and $100 \mathrm{~m}$, in order to be close to the surface, while excluding the contribution of the Ekman currents and the most energetic inertial gravity waves. Because geostrophic profiles show that the vertical shear is negligible within the first hundred meters, a comparison between surface altimetric velocities and mean S-ADCP subsurface velocities is legitimate. The two datasets are compared for the four sections in Fig. 3. They show very coherent large-scale structures. Differences are mainly due to small oceanic features, which are resolved by SADCP but not the gridded altimetry products. Regarding OVIDE 2006, the offshore limit of the surface current system flowing southward along Greenland is not observed at the same location in the two datasets. The presence of ice in this region at the time of the measurements, resulting in missing SLA data, most likely accounts for this discrepancy. The intensity of altimetry velocities seems broadly underestimated compared to SADCP, especially in 2004. This is confirmed by Fig. 4 (left panel), which shows altimetry velocities as a function of S-ADCP velocities: indeed, the intensity of altimetry velocities are $20 \%-30 \%$ weaker than S-ADCP velocities.

Altimetry data used here (upd products) come from an objective mapping of along-track SLA measurements 

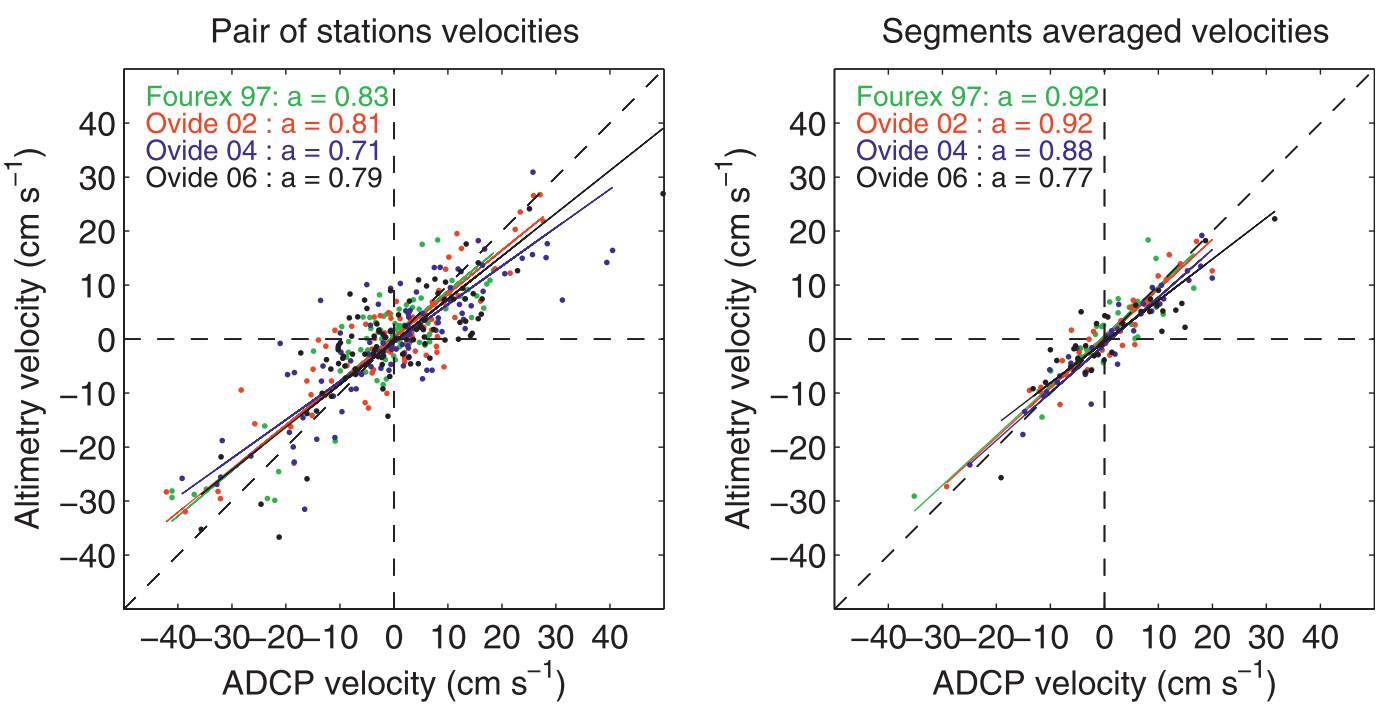

FIG. 4. Altimetry velocities ( $\mathrm{cm} \mathrm{s}^{-1}$, upd series) as a function of corresponding S-ADCP velocities $\left(\mathrm{cm} \mathrm{s}^{-1}\right)$ for the four cruises. (left) Pairs of station velocities (Fig. 3). (right) Velocities averaged on 100-km-long segments (Fig. 6) (pairs and segments lengths are indicated in Table 2 for each cruise). Continuous lines result from orthogonal linear regression, with slopes $(a)$ listed on the figure.

from different satellites. We know from previous studies (Stammer 1997; Le Traon and Dibarboure 1999; Ducet et al. 2000) that altimetry data on scales of less than about $100 \mathrm{~km}$ (depending on latitude) are mainly noise. This was verified through a spectral analysis of both the altimetry and S-ADCP velocity estimates performed for the four sections. While S-ADCP velocities have 1-km resolution, altimetry velocities are provided with a grid scale of about $30 \mathrm{~km}$. To quantitatively compare the spectral contents of both datasets, data were linearly interpolated with a $2-\mathrm{km}$ resolution, and the power spectral density was estimated with a multitaper method (Fig. 5). As expected, the two spectra are equivalent at large wavelengths, but the energy of altimetry velocities decreases more rapidly than that of the S-ADCP velocities at short wavelengths. Thus, features of spatial scales lower than around $100 \mathrm{~km}$ are not resolved by the velocities calculated from the gridded AVISO SLA.

\section{b. Velocities averaged on distances consistent with the altimetry signal resolution}

Our goal here is to use altimetry data as constraints to estimate transports across the sections, similar to the use of S-ADCP measurements by Lherminier et al. (2007). These constraints can only be applied on geostrophic velocity profiles, that is, by pairs of stations; we thus have to take into account the fixed distance between the stations. The spectral analysis of the altimetry velocities suggests that altimetry should be used with a minimum distance of $100 \mathrm{~km}$. We have thus considered consecutive pairs of stations to create segments of about $100 \mathrm{~km}$ (note that we keep all of the CTD stations, because one constraint can be applied to several pairs of stations in the inverse model). The segments were defined in order to gather coherent structures, based on a careful analysis of the sign of the mean S-ADCP velocities. Table 2 shows some statistics on pairs of stations and segments for each of the four sections. Most of the Fourex 1997 stations are $55 \mathrm{~km}$ apart, leading to a definition of segments of $110 \mathrm{~km}$ (three stations). In the OVIDE program the typical distance between stations is $45 \mathrm{~km}$, which gives segments with lengths of $90 \mathrm{~km}$.

Figure 6 shows the differences between altimetry and S-ADCP velocities, plotted both for velocities estimated at the resolution of the pairs of stations and for velocities averaged on segments. As expected, the difference between the two sets appears lower for segments than for pairs. Moreover, the underestimation suggested by the linear fit in Fig. 4 for velocities taken by pairs of stations is also clearly reduced when calculated from data averaged on $100-\mathrm{km}$-long segments, ranging from $8 \%$ to $23 \%$ depending on the cruise (Fig. 4, right panel).

To quantify the deviation between the two independent datasets, the mean value (bias) and the root-mean-square (RMS) of the difference between altimetry and S-ADCP velocities were calculated (Table 3 ). The errors were then normalized by the S-ADCP velocities variances, calculated for each section from the considered velocities. Absolute values are also provided but should be considered with care; they cannot be compared directly because of the inhomogeneous horizontal sampling, depending on the section. The RMS difference has also been 


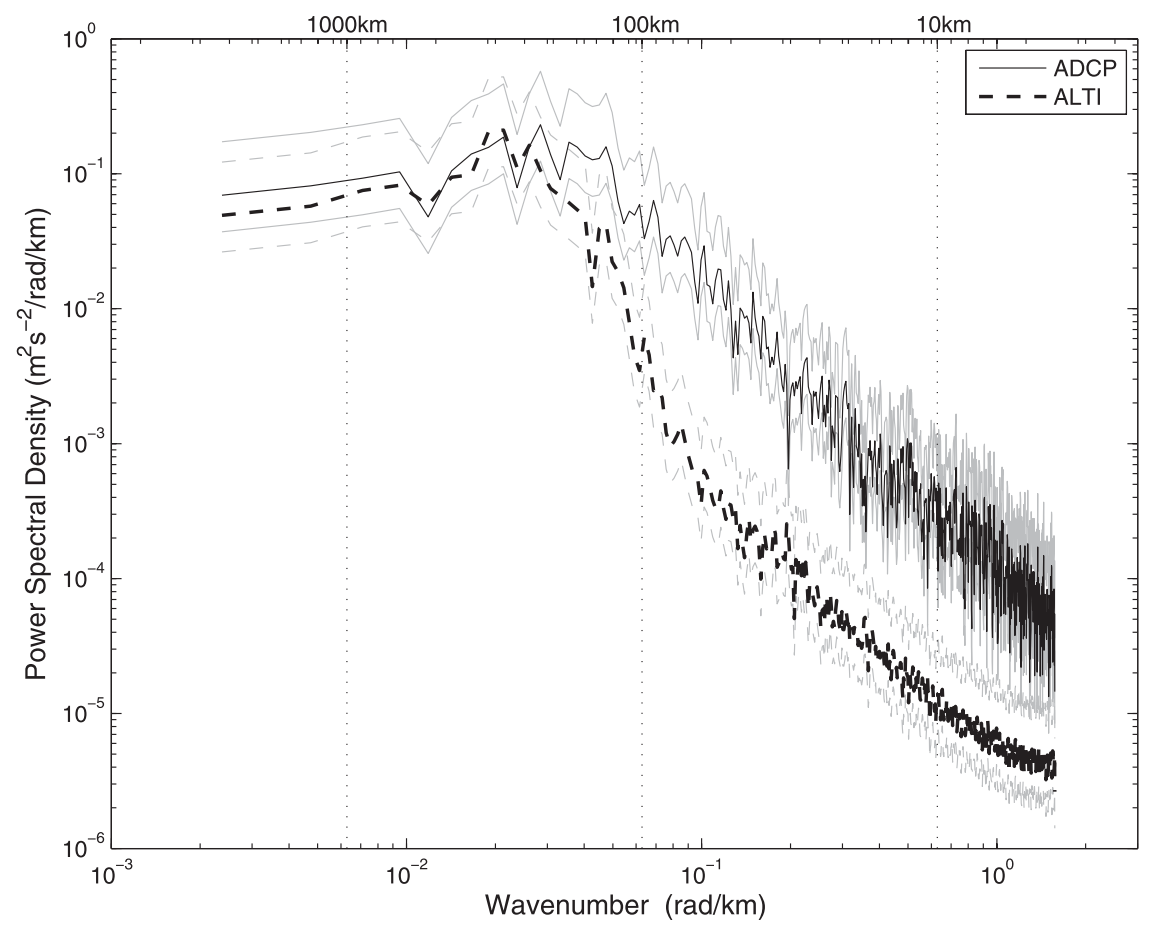

FIG. 5. Spectral density of altimetry and S-ADCP velocities across Fourex and OVIDE sections, on a logarithm axis as a function of wavenumber $\left(\mathrm{rad} \mathrm{km}^{-1}\right)$ [wavelengths are indicated $(\mathrm{km})$ on the top axis]. S-ADCP velocities are plotted in plain black (with the $95 \%$ confidence interval given by the multitaper method in plain gray) and the altimetry velocities in dashed black (with the $95 \%$ confidence interval in dashed gray).

determined with ref altimetry data for the comparison by pairs to refer to homogeneous altimetry data quality.

No important bias appears between the two datasets, with absolute values less than $1 \mathrm{~cm} \mathrm{~s}^{-1}$ (or slightly higher in the OVIDE 2004 case). This is of major interest in the perspective of using these data for reference-level velocity estimation (following section): a bias would indeed modify the top-to-bottom transport distribution across the sections and then modify the final results.

The better agreement when averaging segments is confirmed quantitatively with, for instance, in the OVIDE 2002 case, an RMS difference falling from more than $20 \%$ when considering velocities by pairs of stations to around $10 \%$ when considering averaged velocities on 100-km-length segments.

Results presented in the first column of Table 3 underline the impact of the number of altimeters on the accuracy of the gridded data products. For Fourex 1997, the ref and upd series are the same, because there were no more than two altimeters at work [TOPEX-1 and European Remote Sensing Satellite (ERS)-1]. For OVIDE in June-July 2002 there were three current satellite missions [TOPEX-1, ERS-2, and the Geosat Follow-On $(G F O)$ ], four in June-July 2004 [TOPEX-2, Environmental Satellite (Envisat), Jason, and GFO], and again three in 2006 (Envisat, Jason, and GFO; see CLS (2006)]. The upd gridded ADT that takes into account $G F O$, and TOPEX-2 in 2004, is clearly an improvement over the ref ADT for the three OVIDE sections. This confirms the results of Pascual et al. (2006) who show that using data from four satellites instead of two significantly improves the accuracy of the gridded products for the mesoscale mapping.

Unfortunately, some data of both $G F O$ and Envisat were missing at the time of the OVIDE 2006 cruise. This can explain the larger differences for OVIDE 2006 than for the other cruises despite the three flying altimeters. The large differences observed for Fourex 1997 are due to the limited satellite coverage (only two flying altimeters).

TABLE 2. Statistics on lengths of station pairs and lengths of the segments (group of pairs).

\begin{tabular}{|c|c|c|c|c|c|c|}
\hline & \multicolumn{2}{|c|}{$L_{\text {median }}(\mathrm{km})$} & \multicolumn{2}{|c|}{$L_{\text {mean }}(\mathrm{km})$} & \multicolumn{2}{|c|}{$L_{\text {std }}(\mathrm{km})$} \\
\hline & Pair & Segment & Pair & Segment & Pair & Segment \\
\hline Fourex 1997 & 55 & 111 & 40 & 106 & 20 & 31 \\
\hline OVIDE 2002 & 45 & 93 & 38 & 102 & 12 & 29 \\
\hline OVIDE 2004 & 37 & 93 & 33 & 92 & 13 & 31 \\
\hline OVIDE 2006 & 44 & 92 & 37 & 92 & 12 & 27 \\
\hline
\end{tabular}



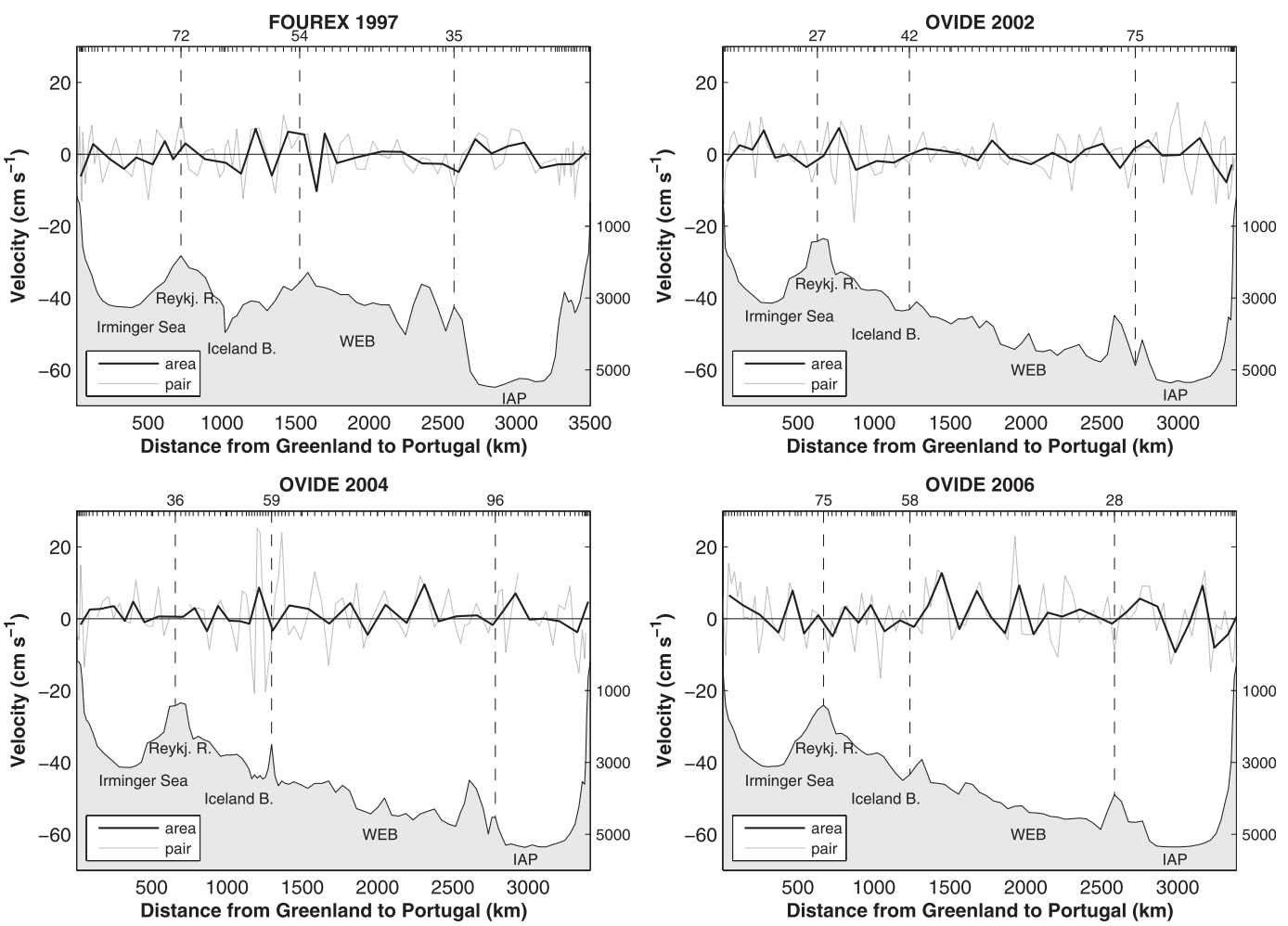

FIG. 6. Difference (left axis) between altimetry velocities and S-ADCP velocities $\left(\mathrm{cm} \mathrm{s}^{-1}\right)$ for segments of around 100-km length (black) and for each pair of stations (gray) as a function of distance from Greenland (km). The numbers of stations (top axis) and bathymetry (right axis) are plotted.

Formal mapping errors provided by AVISO for SLA (Fig. 7) give information regarding the quality of the fluctuating part of the data considered here. The plots reflect the differences of the gridded product quality depending on time and location: globally, upd gridded ADT for Fourex 1997 and OVIDE 2006 appear clearly less accurate than that for OVIDE 2002 and 2004. This is coherent with the numbers of satellite missions available for the mapping.

The normalized results (Table 3) finally show a difference between altimetry and S-ADCP velocities averaged on $100-\mathrm{km}$ segments of $10 \%$ of the signal variance for a configuration of three or four satellites flying, which corresponds to an RMS differences between altimetry and S-ADCP velocity estimates of about $3-3.5 \mathrm{~cm} \mathrm{~s}^{-1}$.

Averaging OVIDE S-ADCP velocities on segments of $100-\mathrm{km}$ length leads to uncertainties of about $1.5 \mathrm{~cm} \mathrm{~s}^{-1}$. An RMS difference between altimetry and S-ADCP velocities slightly higher than $3 \mathrm{~cm} \mathrm{~s}^{-1}$ can thus be explained by an error on altimetry velocities of $3 \mathrm{~cm} \mathrm{~s}^{-1}$ :

$$
\sqrt{1.5^{2}+3^{2}} \approx 3.3 \text {. }
$$

Therefore, according to the comparative study, it seems appropriate to associate an uncertainty of the order of
$3 \mathrm{~cm} \mathrm{~s}^{-1}$ with the considered altimetry velocities computed from AVISO ADT gridded products for a typical configuration of either three or four satellites flying along the OVIDE track.

TABLE 3. Differences between altimetry and S-ADCP velocities averaged between 50- and 100-m depth for velocities at the resolution of the pairs of stations (first three columns) and for velocities averaged on several pairs (segment, last three columns). RMS is given both in percentage of the signal variance and in centimeters per second. Calculations were done with upd altimetry velocities. The bias is computed as the mean of the difference between altimetry and S-ADCP velocities. RMS with ref data is also provided for pairs in percentage of the variance (parentheses, first column).

\begin{tabular}{|c|c|c|c|c|c|c|}
\hline & \multicolumn{3}{|c|}{ Pairs } & \multicolumn{3}{|c|}{ Segments } \\
\hline & \multicolumn{2}{|c|}{ RMS } & \multirow{2}{*}{$\frac{\text { Bias }}{\left(\mathrm{cm} \mathrm{s}^{-1}\right)}$} & \multicolumn{2}{|c|}{ RMS } & \multirow{2}{*}{$\frac{\text { Bias }}{\left(\mathrm{cm} \mathrm{s}^{-1}\right)}$} \\
\hline & $\%(r e f)$ & $\left(\mathrm{cm} \mathrm{s}^{-1}\right)$ & & $\%$ & $\left(\mathrm{~cm} \mathrm{~s}^{-1}\right)$ & \\
\hline $\begin{array}{r}\text { Fourex } \\
1997\end{array}$ & $23.9(23.9)$ & 5.8 & 0.8 & 20.0 & 4.0 & 0.5 \\
\hline $\begin{array}{c}\text { OVIDE } \\
2002\end{array}$ & $20.7(21.4)$ & 6.1 & 0.4 & 10.1 & 3.2 & 0.1 \\
\hline $\begin{array}{c}\text { OVIDE } \\
2004\end{array}$ & $31.4(37.2)$ & 8.2 & -0.8 & 11.2 & 3.5 & -1.2 \\
\hline $\begin{array}{c}\text { OVIDE } \\
2006\end{array}$ & $36.3(45.5)$ & 7.3 & -0.5 & 24.6 & 4.9 & -0.9 \\
\hline
\end{tabular}




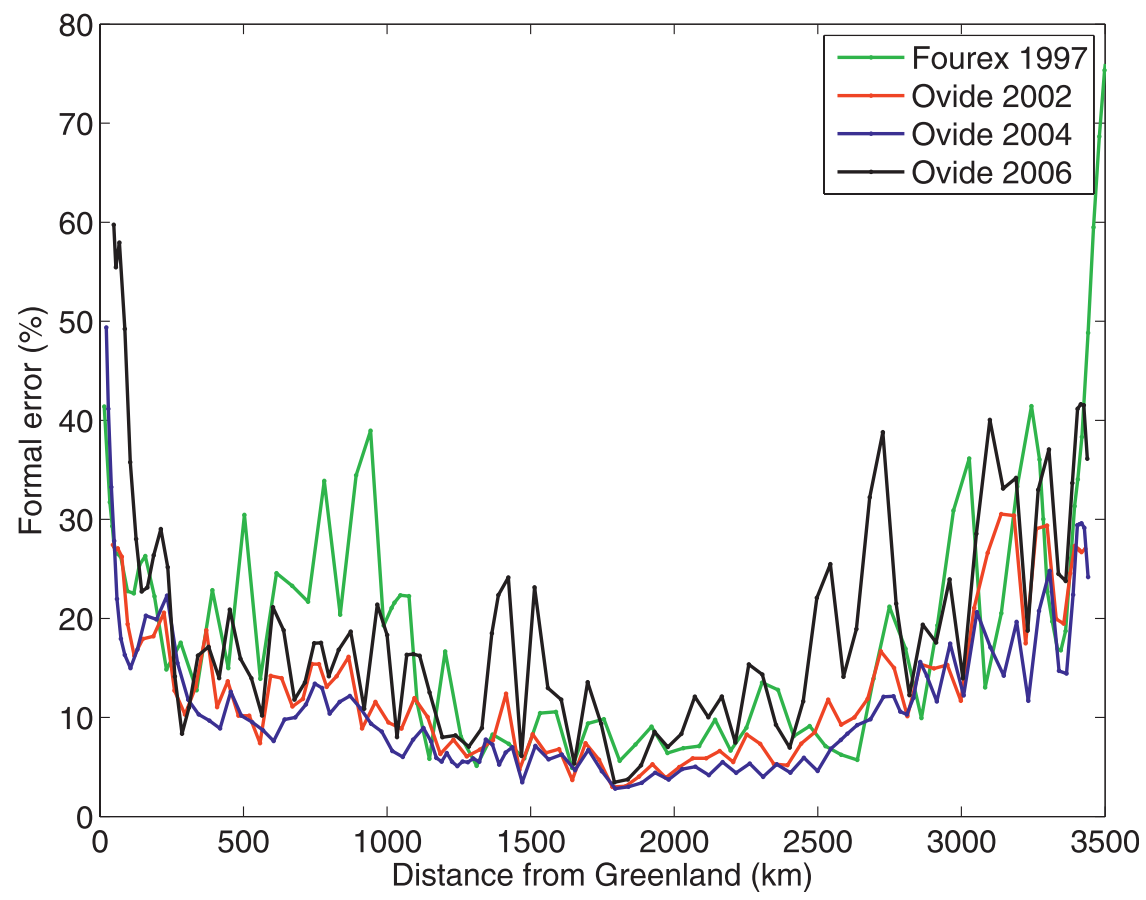

FIG. 7. Formal mapping errors associated with SLA upd gridded products, in percentage of the variance, interpolated at station times and locations along the sections as a function of distance from Greenland ( $\mathrm{km})$.

\section{Altimetry to constrain geostrophic inverse model}

We will now show how the altimetry surface velocities presented above can be used as constraints to estimate absolute geostrophic transports across the OVIDE and Fourex hydrographic sections in a box inverse model.

\section{a. The inverse model}

A linear box inverse model is used to estimate the absolute geostrophic field perpendicular to the sections (e.g., Lherminier et al. 2007). The inverse model (Lux et al. 2000) is based on the least squares formalism and follows the method of Jackson (1979), also described by Mercier (1986). First, geostrophic velocities referenced to selected levels are computed for each station pair from CTD data. Then, the unknown velocities at the reference level are estimated by minimizing the weighted sum of 1) the squared departures from a priori values of the reference-level velocities, 2) the squared residuals of transport constraints derived from direct velocity measurements, and 3) the squared residual of an overall mass conservation constraint. The weights are the associated uncertainties, in the way that constraints with large uncertainties bring less information than those with tight errors.

The reference level for the geostrophic velocity computation from hydrographic measurements and the a priori velocity at this level along with its associated uncertainty formed the a priori solution and are chosen according to the knowledge of the circulation in the region. The a priori solutions described in Lherminier et al. $(2007,2010)$ and Gourcuff (2008) were kept with a reference level at around $1000 \mathrm{~m}$ in the Irminger Sea and in the Iceland Basin, and $3000 \mathrm{~m}$ in the eastern part of the sections. The reference-level velocities were set at 0 with associated uncertainties of $1 \mathrm{~cm} \mathrm{~s}^{-1}$ in the West European Basin and the Iberian Abyssal Plain, $5 \mathrm{~cm} \mathrm{~s}^{-1}$ around Reykjanes Ridge, and $3 \mathrm{~cm} \mathrm{~s}^{-1}$ in the Irminger Sea, except in the western boundary current system where the reference velocity was set at $-10 \pm 15 \mathrm{~cm} \mathrm{~s}^{-1}$ (velocities with a southward component are negative). The offshore limit of this southward boundary flow was defined as the offshore limit of the East Greenland Irminger Current (EGIC), which is also referred to as the East Greenland Current (EGC) in literature, but herein explicitly includes the southward flow of saline water from the Irminger Current recirculation (Pickart et al. 2005; Daniault et al. 2011a), as determined from the hydrographic data.

\section{b. Constraints}

An important step in this inverse procedure is to estimate the transport constraints from direct velocity measurements and their associated uncertainties. They 
are determinant in estimating the transports in the subpolar gyre, a region of intense barotropic transports. The constraints are set to the model as transports and their associated uncertainties as an error covariance matrix. We have applied them on a 100-m-thick layer at surface, multiplying the velocities computed from AVISO ADT gridded products by the distance of influence and the $100-\mathrm{m}$ depth. The comparison between altimetry and collocated S-ADCP velocities (section 3), and more specifically the spectral analysis performed on the two signals, showed that the minimum spatial scale resolved by velocities computed from gridded altimetry products in the subpolar region was $\sim 100 \mathrm{~km}$. This means that altimetry velocities are not redundant only when averaged on distances greater or equal to $100 \mathrm{~km}$. We chose to apply the altimetry constraints on the previously defined segments of about $100 \mathrm{~km}$, thus avoiding computing nondiagonal elements in the covariance matrix of the constraints.

The uncertainties associated with the constraints impact the model behavior through their relative weights in the least squares minimization. Uncertainties in altimetry velocities are complex, with the following two contributors: one is the anomaly component that can eventually be deduced from the height formal mapping error data (Le Traon and Dibarboure 1999), and the other one is the mean circulation component, which is unknown. Following results of the comparison between altimetry and S-ADCP velocities (section 3 ) would lead to allocating uncertainties of about $3 \mathrm{~cm} \mathrm{~s}^{-1}$ to the altimetry velocities used to determine the transport constraints. However, the formal SLA mapping error plotted in Fig. 7 clearly displays some spatial variability of the fluctuating part of the velocities with values in the center of the basin that are lower than those close to the boundary for each of the four sections. This behavior can be explained close to the coast by the decrease in the number of available altimetry data, but also more generally by the local values of spatial and temporal correlation scales used in the mapping procedure.

At the western boundary, both the EGIC and the deep western boundary current flow southward, the first above the second. The velocity there is thus southward and particularly intense from the surface to the bottom. The barotropic character of this circulation makes the transport constraints essential in this region where the velocity at the reference level, whatever the selected depth, is significantly different from zero. This intense southward transport must be compensated by a net northward transport across the remaining part of the section. A large uncertainty on the western boundary transports would thus lead to large uncertainties on integrated quantities, such as the heat transport. The presence of ice can locally disrupt altimetry measurements and alter the mapping product quality close to the Greenland coast (Fig. 7). As stated earlier, this was the case in June 2006 during the OVIDE cruise when the ice coverage at the shelf break resulted in especially high error for mapped SLA at the southern tip of Greenland. In this specific region, we thus decided to use the formal mapping error to weight the generic $3 \mathrm{~cm} \mathrm{~s}^{-1}$ uncertainty to take into account the error increase at the western boundary in the inverse procedure.

Regarding the remaining constraints, out of the western boundary, sensitivity tests were performed showing that the chosen model configuration (constraints on segments and uncertainties around $3 \mathrm{~cm} \mathrm{~s}^{-1}$ ) gives the same results as long as the uncertainties on different segments do not deviate by more than $1 \mathrm{~cm} \mathrm{~s}^{-1}$.

In summary, we set a uniform uncertainty of $3 \mathrm{~cm} \mathrm{~s}^{-1}$ on each segment of the interior circulation, that is, everywhere except in the western boundary region, where the value of $3 \mathrm{~cm} \mathrm{~s}^{-1}$ was modulated by the local mapping error percentage following Eq. (2),

$$
\operatorname{Verr}_{\mathrm{WB}}=3 \times \frac{p_{\mathrm{WB}}}{p_{\text {mean }}},
$$

where $p_{\mathrm{WB}}$ corresponds to the mapping error percentage at the western boundary and $p_{\text {mean }}$ corresponds to the averaged mapping error percentage along the section (Fig. 7).

To get realistic transport across OVIDE and Fourex sections from the inverse model, we also apply a global volume constraint. A hydrology budget based on Nordic Seas exports from literature values leads to a volume constraint of $1 \mathrm{~Sv}\left(1 \mathrm{~Sv} \equiv 10^{6} \mathrm{~m}^{3} \mathrm{~s}^{-1}\right)$ northward across OVIDE and Fourex closed sections (Gourcuff 2008). Following the analysis of Ganachaud (2003), we associated an uncertainty of $3 \mathrm{~Sv}$ with this volume constraint to account for ageostrophy and nonsynopticity of the measurements.

\section{c. Results and comparison with $S$-ADCP inversions}

The inverse model provides reference velocity estimates that are the closest in a least squares sense to the a priori values and the constraints weighted by the associated uncertainties. As an example, Fig. 8 shows the comparison between reference velocities before and after inversion in June 2006. After inversion, uncertainties associated with velocities are still large (they are mainly determined by the standard errors of the altimetry constraints). However, resulting from correlations between these uncertainties, the standard errors associated with the transport estimates of the main currents or with the heat flux estimate are much smaller. 


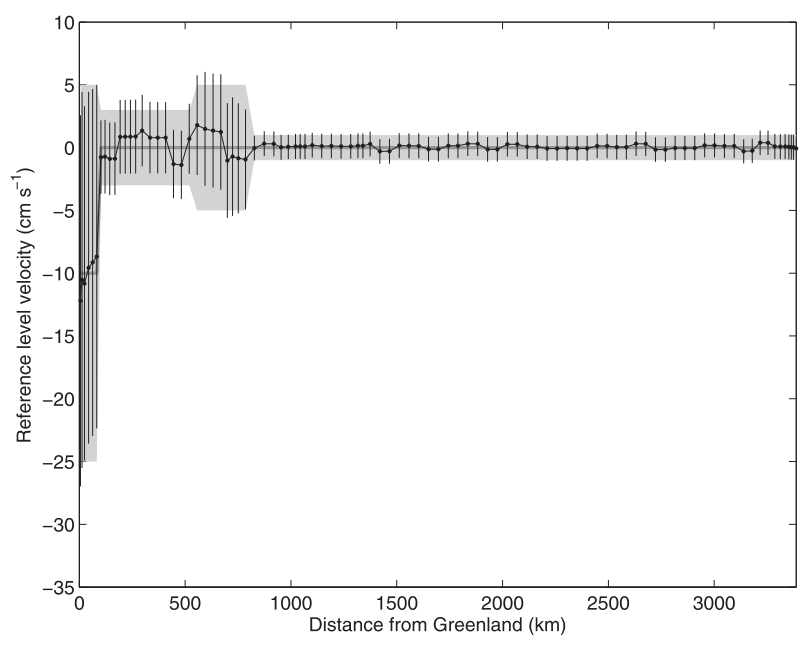

FIG. 8. Reference-level velocities, a priori (gray, with uncertainties shaded) and after the altimetry inversion (black, with uncertainties as black bars) for the OVIDE 2006 section. Velocities $\left(\mathrm{cm} \mathrm{s}^{-1}\right)$ are plotted as a function of distance from Greenland $(\mathrm{km})$.

The transports of the two main currents intersected by Fourex-OVIDE sections, the EGIC, and the North Atlantic Current (NAC), as well as the heat flux across the sections, are now examined in more details.

The EGIC transport is defined as the total transport from surface to the isopycnal $\sigma_{2}=36.94\left(\sigma_{0} \approx 27.8\right)$, the classical upper bound of the deep western boundary current flowing below. Across the OVIDE section, the NAC has already split in several branches (Lherminier et al. 2010). We thus chose to simply consider here the North Atlantic Current across OVIDE as the total (net) flow between the Eriador Ridge (the southeastern boundary of the Maury Channel, see Fig. 1) and the Portugal coast, from the surface to $\sigma_{1}=32.35$ (Lherminier et al. 2007). For Fourex, the western NAC limit is taken at the southeastern bound of the Charlie Gibbs Fracture Zone. Its eastern boundary is also taken as the Portugal coast. Transport together with their uncertainties as provided by the inverse model are given in Table 4 and plotted on Fig. 9.

Despite large uncertainties, especially for the EGIC flowing in an area where altimetry constrains are less accurate, the results highlight a variability that compares favorably with S-ADCP inversions (Fig. 9). Uncertainties are larger than the ones of S-ADCP inversions and part of the variability is smoothed, with, notably, less extreme values in 2006. However, the tendency is the same, with high transports in 1997, intermediate transports in 2002 and 2004, and weak transports in 2006. NAC and heat transports are significantly weaker in 2006 than in 2004, within the error bars. The NAC represents the northward eastern branch of the cyclonic large-scale subpolar circulation, with the EGIC being
TABLE 4. Absolute transport of the EGIC, the NAC, and total heat transport (HT) across the four Fourex/OVIDE sections, as estimated by the inverse model constrained with altimetry (bold). Results from S-ADCP inversions are also indicated in parentheses. Transports are expressed in Sverdrups and HT in $10^{15} \mathrm{~W}$. Errors represent uncertainties given by the model.

\begin{tabular}{lccc}
\hline \hline & EGIC $(\mathrm{Sv})$ & NAC $(\mathrm{Sv})$ & HT $\left(10^{15} \mathrm{~W}\right)$ \\
\hline Fourex 1997 & $\mathbf{2 3 . 1} \pm \mathbf{6 . 6}$ & $\mathbf{2 8 . 1} \pm \mathbf{3 . 1}$ & $\mathbf{0 . 7 1} \pm \mathbf{0 . 0 9}$ \\
& $(25.4 \pm 0.6)$ & $(26.7 \pm 1.7)$ & $(0.70 \pm 0.06)$ \\
OVIDE 2002 & $\mathbf{1 8 . 5} \pm \mathbf{5 . 4}$ & $\mathbf{1 9 . 5} \pm \mathbf{2 . 4}$ & $\mathbf{0 . 5 1} \pm \mathbf{0 . 0 8}$ \\
& $(22.4 \pm 1.1)$ & $(19.4 \pm 1.7)$ & $(0.45 \pm 0.06)$ \\
OVIDE 2004 & $\mathbf{2 2 . 3} \pm \mathbf{5 . 5}$ & $\mathbf{2 3 . 8} \pm \mathbf{1 . 8}$ & $\mathbf{0 . 5 7} \pm \mathbf{0 . 0 7}$ \\
& $(27.1 \pm 0.9)$ & $(25.8 \pm 1.4)$ & $(0.51 \pm 0.04)$ \\
OVIDE 2006 & $\mathbf{1 5 . 2} \pm \mathbf{5 . 5}$ & $\mathbf{1 5 . 3} \pm \mathbf{1 . 9}$ & $\mathbf{0 . 4 0} \pm \mathbf{0 . 0 7}$ \\
& $(15.9 \pm 0.6)$ & $(16.7 \pm 1.3)$ & $(0.29 \pm 0.04)$ \\
\hline
\end{tabular}

the western southward branch. The intensification of both the NAC and the EGIC between 2002 and 2004, illustrating the horizontal circulation intensification (Lherminier et al. 2010), is also visible in the new results with altimetry constraints.

Note that the inverse model was run with combined constrains (S-ADCP and altimetry) to simulate gaps in the S-ADCP data, because equipments at sea has the propensity to fail from time to time. The resulting absolute transports were consistent with Table 4, showing intermediate error values.

\section{Discussion}

Thanks to recent progress in geoid knowledge, which is needed for absolute surface velocity determination from altimetry data, absolute altimetry velocities have been considerably improved in recent years. The comparison between, on the one hand, the altimetry velocities calculated from gridded sea level anomaly data (AVISO) combined with the Rio05 mean circulation (Rio and Hernandez 2004), and, on the other hand, Fourex and OVIDE S-ADCP velocities, shows a good agreement between these two independent surface velocity datasets, with the large-scale structures being well correlated. It enabled us to estimate the length scales that are really resolved by the gridded altimetry data considered, which appears to be larger or equal to $100 \mathrm{~km}$. Averaging velocities on such distances, we found no bias and an RMS difference between altimetry velocities and $\mathrm{S}$-ADCP velocities of $3.3 \mathrm{~cm} \mathrm{~s}^{-1}$. This result is novel in that, in view of the S-ADCP accuracy, it yields a quantitative estimate of the quality of absolute surface velocity derived from gridded altimetry products $\left(3 \mathrm{~cm} \mathrm{~s}^{-1}\right)$.

An estimation of uncertainties on altimetry velocities was thus made possible, with values that were slightly higher than the ones associated with S-ADCP, but of the 

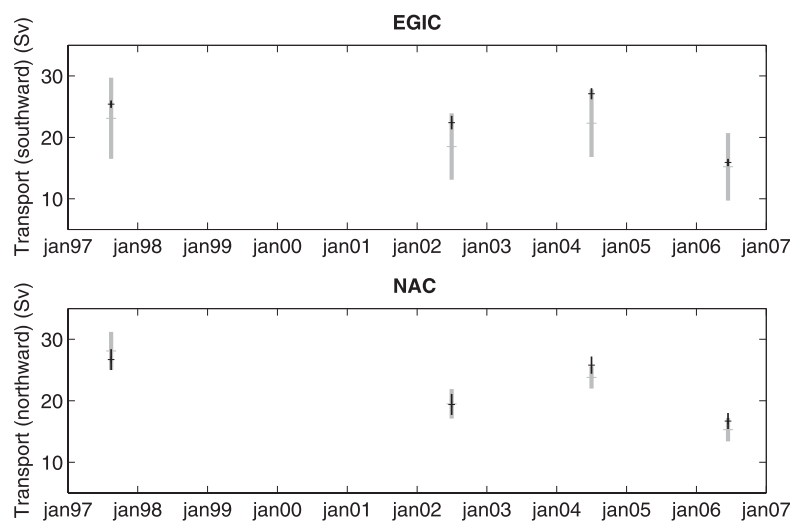

HT

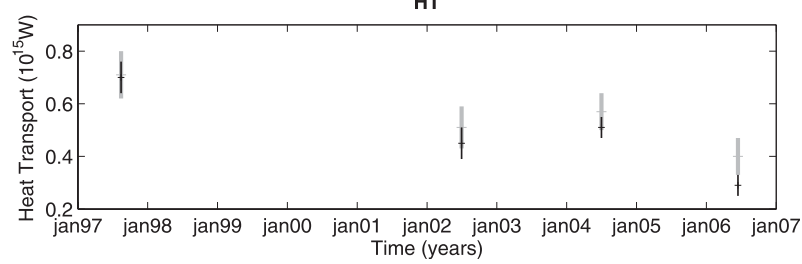

FIG. 9. (top to bottom) Transports of the East Greenland Irminger Current, the North Atlantic Current (Sv), and total heat transport $\left(10^{15} \mathrm{~W}\right)$ obtained with the inverse model constrained with S-ADCP data (black) and with altimetry data (gray) for four occurrences of the Fourex-OVIDE section.

same order. This leads to the determination of the reference-level velocity across a hydrographic section. Indeed, this work shows how meaningful transport estimates across a hydrographic section was obtained at the section dates using a geostrophic box inverse model constrained with altimetry measurements. Although local uncertainties are larger than when the model is constrained with currents measured by S-ADCP, the two methods give consistent results for Fourex and OVIDE sections, with uncertainties on large-scale transports $\sim 50 \%$ higher with altimetry than with S-ADCP constraints. The heat transport, as well as the NAC transport (both of which are linked, with the NAC transporting warm waters), are indeed robust. We find the same variability with both sets of constraints for three important quantities (NAC and EGIC transport and total heat transport). Significant variability could be found between 1997 and 2006 for the EGIC and between 1997 and 2006, but also between 2004 and 2006 for the NAC and heat transports.

The method presented here displays the quality and usefulness of altimetry products currently available and shows that the MDT is known with enough precision in the North Atlantic to estimate surface-to-bottom transports across hydrographic sections. Moreover, the data quality should improve in the near future thanks to new geoid models [the Gravity Field and Steady-State Ocean Circulation Explorer (GOCE) project] and then, hopefully, allow us to reduce uncertainties associated with transport estimates.

Our results highlight the difficulty of the actual altimetry sampling to represent the total EGIC variability along the coast. This issue of coastal altimetry is actually under investigation (Lebedev et al. 2007; Desportes et al. 2007), and early products have been provided by AVISO in the frame of the Prototype Innovant de Système de Traitement pour l'Altimétrie Côtière (PISTACH) project, which could improve the results (these products were not available when this work was done). The determination of absolute transports over western boundary regions where the circulation is usually strongly barotropic is not possible with hydrography alone. Despite the increased errors in altimetry measurements close to the coasts, we have proved here the benefits of using actual absolute altimetry surface velocities products to supply the complementary information particularly required in western boundary regions. In this respect, the recent study of Daniault et al. (2011b) shows how these products can be used to study the variability of the EGIC absolute transport over $17 \mathrm{yr}$. The altimetry data could also be useful to fill the gaps in ADCP data that have sometimes occurred in cruises or in cases of a complete lack of in situ velocity data in historical cruises. Sea level anomaly data are available for the global ocean with a weekly resolution and could be used to estimate surface-to-bottom transports across the many hydrological sections done in the 90s within the WOCE project, and then lead to a better knowledge of ocean circulation variability on a temporal scale of more than $15 \mathrm{yr}$.

Roemmich and Wunsch (1982) predicted the role of satellite SSH measurement to improve our knowledge of ocean circulation. The usefulness of absolute altimetry data in time-dependent models has already been widely proved through projects like Simple Ocean Data Assimilation (SODA; Carton et al. 2000) and Estimating the Circulation and Climate of the Ocean (ECCO; Wunsch et al. 2008). Our study constitutes a new example of the complementary aspects of altimetry data and in situ measurements, providing a means for further progress in the determination of the reference-level velocity issue in geostrophy calculations.

Acknowledgments. The altimeter products were produced by Ssalto/Duacs and distributed by AVISO, with support from CNES (http://www.aviso.oceanobs.com/ duacs/). The authors wish to acknowledge the colleagues and ship crews who collected all the data discussed in this paper. For this work, Claire Gourcuff was supported by CNES and IFREMER, Pascale Lherminier and Pierre Yves Le Traon by IFREMER, and Herlé Mercier by CNRS. The OVIDE project mainly relies on funds from IFREMER, INSU, and LEFE. 


\section{REFERENCES}

Álvarez, M., F. Pérez, H. Bryden, and A. F. Ríos, 2004: Physical and biochemical transports structure in the North Atlantic subpolar gyre. J. Geophys. Res., 109, C03027, doi:10.1029/ 2003JC002015.

Bacon, S., 1997: Circulation and fluxes in the North Atlantic between Greenland and Ireland. J. Phys. Oceanogr., 27, 1420-1435.

Bersch, M., 1995: On the circulation of the northeastern North Atlantic. Deep-Sea Res. I, 42, 1583-1607.

Bruinsma, S., J.-M. Lemoine, R. Biancale, and N. Valès, 2010: CNES/GRGS 10-day gravity field models (release 2) and their evaluation. Adv. Space Res., 45, 587-601, doi:10.1016/ j.asr.2009.10.012.

Carton, J. A., G. Chepurin, X. Cao, and B. Giese, 2000: A Simple Ocean Data Assimilation Analysis of the global upper ocean 1950-95. Part I: Methodology. J. Phys. Oceanogr., 30, 294-309.

Chelton, D. B., R. A. deSzoeke, M. G. Schlax, K. E. Naggar, and N. Siwertz, 1998: Geographical variability of the firstbaroclinic Rossby radius of deformation. J. Phys. Oceanogr., 28, 433-460.

CLS, 2006: SSALTO/DUACS user handbook: (M)SLA and (M)ADT near-real time and delayed time products. Version 1rev4 January 2006 CLS-DOS-NT-06.034, 46 pp.

Daniault, N., H. Mercier, and P. Lherminier, 2011a: Circulation and transport at the southeast tip of Greenland. J. Phys. Oceanogr., 41, 437-457.

,-- , and ——, 2011b: The 1992-2009 transport variability of the East Greenland-Irminger Current at $60^{\circ} \mathrm{N}$. Geophys. Res. Lett., L07601, doi:10.1029/2011GL046863.

Desportes, C., E. Obligis, and L. Eymard, 2007: On wet tropospheric correction for altimetry in coastal regions. IEEE Trans. Geosci. Remote Sens., 45, 2139-2149, doi:10.1109/ TGRS.2006.888967.

Ducet, N., P. Y. Le Traon, and G. Reverdin, 2000: Global highresolution mapping of ocean circulation from TOPEX/ Poseidon and ERS-1 and -2. J. Geophys. Res., 105 (C8), 19 477-19 498.

Egbert, G., A. Bennett, and M. Foreman, 1994: TOPEX/Poseidon tides estimated using a global inverse model. J. Geophys. Res., 99 (C12), 24 821-24 852.

Fischer, J., P. Brandt, M. Dengler, M. Müller, and D. Symonds, 2003: Surveying the upper ocean with the ocean surveyor: A new phased array Doppler current profiler. J. Atmos. Oceanic Technol., 20, 742-751.

Fu, L.-L., and D. B. Chelton, 2001: Large-scale ocean circulation. Satellite Altimetry and Earth Sciences, L.-L. Fu and A. Cazenave, Eds., Academic Press, 133-169.

Ganachaud, A., 2003: Error budget of inverse box models: The North Atlantic. J. Atmos. Oceanic Technol., 20, 1641-1655.

—, C. Wunsch, M.-C. Kim, and B. Tapley, 1997: Combination of TOPEX/POSEIDON data with a hydrographic inversion for determination of the oceanic general circulation and it relation to geoid accuracy. Geophys. J. Int., 128, 708-722.

Gourcuff, C., 2008: Etude de la variabilité de la circulation du gyre subpolaire de l'Atlantique Nord à partir des données OVIDE et de mesures satellitaires. Ph.D. thesis, Université de Bretagne Occidentale, $212 \mathrm{pp}$.

Jackson, D. D., 1979: The use of a priori data to resolve nonuniqueness in linear inversion. Geophys. J. Roy. Astron. Soc., 57, 137-157.
Joyce, T. M., C. Wunsch, and S. D. Pierce, 1986: Synoptic Gulf Stream velocity profiles through simultaneous inversion of hydrographic and acoustic Doppler data. J. Geophys. Res., 91 (C6), 7573-7585.

_- A. Hernandez-Guerra, and W. M. Smethie, 2001: Zonal circulation in the NW Atlantic and Caribbean from a meridional World Ocean Circulation Experiment hydrographic section at 66ํ‥ J. Geophys. Res., 106 (C10), 22 095-22 113.

King, B. A., E. Firing, and T. M. Joyce, 2001: Shipboard observations during WOCE. Ocean Circulation and Climate, G. Siedler, J. Church, and J. Gould, Ed., Academic Press, 99-122.

Krauss, W., 1995: Currents and mixing in the Irminger Sea and in the Iceland Basin. J. Geophys. Res., 100 (C6), 10 851-10 871.

Lebedev, S., and Coauthors, 2007: Exploiting satellite altimetry in coastal ocean through the ALTICORE project. Russ. J. Earth Sci., 10, ES1002, doi:10.2205/2007ES000262.

Le Traon, P. Y., and G. Dibarboure, 1999: Mesoscale mapping capabilities of multiple-satellite altimeter missions. J. Atmos. Oceanic Technol., 16, 1208-1223.

$\longrightarrow$, and - 2002: Velocity mapping capabilities of present and future altimeter missions: The role of high-frequency signals. J. Atmos. Oceanic Technol., 19, 2077-2087.

Lherminier, P., H. Mercier, C. Gourcuff, M. F. Alvarez, S. Bacon, and C. Kermabon, 2007: Transport across the 2002 GreenlandPortugal Ovide section and comparison with 1997. J. Geophys. Res., 112, C07003, doi:10.1029/2006JC003716.

$\longrightarrow,-$, T. Huck, C. Gourcuff, F. F. Pérez, P. Morin, A. Sarafanov, and A. Falina, 2010: The Atlantic meridional overturning circulation and the subpolar gyre observed at the A25-OVIDE section in June 2002 and 2004. Deep-Sea Res. I, 57, 1374-1391, doi:10.1016/j.dsr.2010.07.009.

Lumpkin, R., K. G. Speer, and K. P. Koltermann, 2008: Transports across $48^{\circ} \mathrm{N}$ in the Atlantic Ocean. J. Phys. Oceanogr., 38, $733-752$.

Lux, M., H. Mercier, and M. Arhan, 2000: Interhemispheric exchanges of mass and heat in the Atlantic Ocean in JanuaryMarch 1993. Deep-Sea Res. I, 48, 605-638.

Mercier, H., 1986: Determining the general circulation of the ocean: A nonlinear inverse problem.J. Geophys. Res., 91 (C4), 5103-5110.

Pascual, A., Y. Faugère, G. Larnicol, and P.-Y. Le Traon, 2006: Improved description of the ocean mesoscale variability by combining four satellite altimeters. Geophys. Res. Lett., 33, L02611, doi:10.1029/2005GL024633.

Pickart, R. S., D. J. Torres, and P. S. Fratantoni, 2005: The East Greenland Spill Jet. J. Phys. Oceanogr., 35, 1037-1053.

Reigber, C., and Coauthors, 2003: The CHAMP-only earth gravity field model EIGEN-2. Adv. Space Res., 31, 1883-1888.

Rio, M.-H., and F. Hernandez, 2003: High-frequency response of wind-driven currents measured by drifting buoys and altimetry over the world ocean. J. Geophys. Res., 108, 3283, doi:10.1029/2002JC001655.

_ the world ocean from altimetry, in situ measurements, and a geoid model. J. Geophys. Res., 109, C12032, doi:10.1029/2003JC002226.

— , P. Schaeffer, F. Hernandez, and J.-M. Lemoine, 2005: The estimation of the ocean Mean Dynamic Topography through the combination of altimetric data, in-situ measurements and GRACE geoid: From global to regional studies. Proc. GOCINA Int. Workshop, Luxembourg City, Luxembourg, European Center for Geodynamics and Seismology and Cosponsors. [Available online at http://gocinascience.spacecenter.dk/ publications/5_4_rio.pdf.] 
Roemmich, D., and C. Wunsch, 1982: On combining satellite altimetry with hydrographic data. J. Mar. Res., 40 (Worthington Volume Suppl.), 605-619.

Sarafanov, A., A. Falina, P. Lherminier, H. Mercier, A. Sokov, and C. Gourcuff, 2010: Assessing decadal changes in the Deep Western Boundary Current absolute transport southeast of Cape Farewell, Greenland, from hydrography and altimetry. J. Geophys. Res., 115, C11003, doi:10.1029/ 2009JC005811.

Saunders, P. M., and B. A. King, 1995: Bottom currents derived from a shipborne ADCP on WOCE Cruise A11 in the South Atlantic. J. Phys. Oceanogr., 25, 329-347.
Stammer, D., 1997: Global characteristics of ocean variability estimated from regional TOPEX/Poseidon altimeter measurements. J. Phys. Oceanogr., 27, 1743-1769.

Tapley, B. D., and Coauthors, 1996: The Joint Gravity Model 3. J. Geophys. Res., 101 (B12), 28 029-28 049.

Wunsch, C., 1978: The North Atlantic general circulation west of $50^{\circ} \mathrm{W}$ determined by inverse methods. Rev. Geophys., 16, 583-620. 1996: The Ocean Circulation Inverse Problem. Cambridge University Press, $458 \mathrm{pp}$

- and Coauthors, 2008: The global general circulation of the ocean estimated by the ECCO Consortium. Oceanography, 22, 88-103. 